
SLOVACA

Volume 22, No. 1, 2021, 30 - 39

\title{
TESTING OF WATER EVALUATION AND PLANNING (WEAP) MODEL FOR WATER RESOURCES MANAGEMENT IN THE HRON RIVER BASIN
}

\author{
Miroslav Kandera*, Roman Výleta, Anna Liová, Zuzana Danáčová, Lubica Lovasová
}

\begin{abstract}
The assessment of water resources and the availability of water in river basins is one of the main tasks enabling efficient water management. One of the bases for the Water Plan of the Slovak Republic is a retrospective water management balance of the amount of surface water in Slovakia, which compares the requirements for water with the usable amount of water. As part of the efforts to improve the plan, the possibility of modelling the water management balance of surface waters using appropriate software for the integrated planning of water resources was outlined. The Water Evaluation and Planning (WEAP) software was selected to test this modelling according to the current methodology. In the Hron river basin, a time series in a monthly time step of data input in the period 2000-2019 was selected. The focus was on the compatibility of the current methodology of the water management balance and methods of modelling it in the WEAP software. The output is a river basin model capable of producing outputs above the level of the original processing of the water management balance, while the compilation of the graphic and data structure of the modelled river basin is fully automated, mainly by using command lines. This modelling approach has shown that, thanks to the possibility of creating new variables within the data structure, it is possible to achieve the required level of compatibility with the set methodology for water management balances. The results demonstrate that the WEAP could be an easy-to-use model building tool for the optimal and successful development, planning and forecasting of water management in space and over time in Slovakia.
\end{abstract}

KEY WORDS: WEAP, Water Resources Management, Water Supply and Demand, Hron River Basin

\section{Introduction}

In Slovakia, there has recently been increasing interest in reassessing the structure and valid methodology of the water management balance of the amount and regime of surface waters in previous year. It is important to realize that it is no longer nowadays possible to think exclusively about water use in addressing this issue, but the balances should also include the needs of ecosystems (not just respecting the ecological limits of water use) and ongoing global changes. With regard to the goals of sustainable development in water management, the balances are based not only on the knowledge and definition of water resources, but also on the impact on water resources over time and in space. The chief requirement for the correct evaluation of the balance status of water bodies within water management is the achievement of a sufficient level of the quality and quantity of the method used for processing information based on the natural regime of water in nature and the individual impacts of water use.

A considerable amount of simulation software integrated into interactive graphic interfaces is currently available around the world for research and the solutions to water management and water redistribution in river basins, all of which create simplified representations of real-world systems. They serve both to plan and manage the use of water in river basins but are also suitable to facilitate the involvement of stakeholders in the planning and decision-making process at various levels (Assaf et al., 2008). They have also been used and proved successful in countries that have already established a quality monitoring network and methodology for obtaining data on water use, e.g., the Slovak Republic, other countries in Western Europe, North America, etc. Although each model has its own special features, they are all designed to facilitate the input and storage of data, the retrieval and display of the geographical, hydrological and, depending on the type of model and application, socio-economic data associated with specific river basins or regions. Over the years, they developed their so-called genericity, i.e., a set of features that programs of this kind have in common, whether they include the method of simulation or the creation of the data or schematic structure of a river basin and a river network. However, each software has its own special features and user interface that was specified for each software when it was created and which is then supplemented over the years with features 
that are primarily helpful to the user, thereby reinforcing this common genericity. Their advantage is in their ability to solve variations with the help of computers, both in the sources and in the water requirements. Due to the mentioned genericity of the software developed to solve water balance issues, the selection of a specific software without testing it and its properties is a complex question. The best-known balance simulation models include AQUATOOL (Andreu et al., 1996), MIKE HYDRO BASIN (DHI, 2003), MODSIM (Labadie, 2005), RIBASIM (WL/Delft Hydraulics, 2007), WARGI (Sechi and Sulis, 2009), WBalMo (Kaden et al., 2006), and WEAP (Yates et al., 2005).

The paper deals with testing a balance simulation model for modeling the quantitative water management balance of surface waters, taking into account the valid methodology of the Slovak Republic. In Slovakia, simulation balance models have not yet been fully applied in water management; therefore, research in this area could be helpful not only for planning and solving problem areas (detailed balances) but also to facilitate the involvement of stakeholders in the planning and decision-making process at various levels. In this paper, the selection of the software was carried out based on the available information and considering the predetermined criteria, such as the purpose of its use, availability, requirements for the preparation and compatibility of input data, software updates, clarity of the user environment, software limits, etc. In this study, the Water Evaluation and Planning (WEAP) software was selected for the specific resolution and analysis of the water management balance of Slovakia according to the valid methodology in the pilot river basin (Hron river basin). The authors aim to evaluate its possibilities for application in our geographical conditions.

\section{Material and methods}

\section{Actual methodology of the water management balance of surface waters}

The water management balance has been used in Slovakia to frame water planning since 1973 (European Union, 2015). According to the decree on the Water Act No. 418/2010 Coll., as later amended, the water management balance compares the requirements for water with the usable amount of water and its quality. The water requirements stand for abstractions of the surface water, groundwater, water discharges, and special water. The water management balance is prepared for the purposes of the Water Plan of Slovakia according to an approved time plan using approved data acquisition procedures, processing methodologies and forms of outputs. It is processed separately for surface waters and for groundwater, as well as for the quantity and quality of the water.

This paper focuses only on the quantitative water management balance of surface water. In term of the quantity of surface water, the universal relationship of water management considers all the most impactful types of the elements of this inequality between sources and needs, i.e., natural water resources, water abstractions, water discharges, the impact of reservoirs, water transfers, and the minimum required flow (Poórová, 2007). The positive or negative impact of manipulation on reservoirs and water transfers is determined by whether they improve or reduce the streamflow. The relationship is given by:

$$
\begin{aligned}
& \text { RESOURCES }<=>N E E D S \\
& C \pm N \pm P<=>O-V+M Q
\end{aligned}
$$

where:

$$
\begin{array}{ll}
\mathrm{C} & \text { - natural water resources, } \\
\mathrm{N} & \text { - activity of reservoirs, } \\
\mathrm{P} & \text { - water transfers, } \\
\mathrm{V} & \text { - water discharges, } \\
\mathrm{O} & \text { - water abstractions, } \\
\mathrm{MQ} & \text { - minimum required flows. }
\end{array}
$$

The water management balance of surface water is evaluated in balance profiles that cover important locations for water use, the effect of water reservoirs, and water transfers, thereby focusing on the availability of the hydrological information with the maximum connection to the existing network of water gauging stations. The characteristics in every balance profile are evaluated for the 12 months of the calendar year and the annual streamflow average value (Danáčová et al., 2011). The main characteristic describing a balance profile's condition is the balance status. It is a dimensionless characteristic evaluated as two alternatives:

i) As BSC, i.e., evaluating what would be the balance situation under natural flows when considering the realized abstractions as well as water discharges, while the developed form of the relationship appears as:

$$
B S C=\frac{E-X \pm N \pm P}{M Q-X}
$$

ii) BSENP (equals BSC) is the balance status that is focused on an assessment of a stream affected by a reservoir or water transfer. In its developed form, it is given by the following equation:

$$
B S E N P=\frac{E-X}{M Q-X}
$$

where:

BSC, BSENP - value of balance status [-],

E $\quad-$ affected streamflow $\left[\mathrm{m}^{3} \mathrm{~s}^{-1}\right]$,

$\mathrm{N}$ - changes in the volume of water in the reservoir $\left[\mathrm{m}^{3} \mathrm{~s}^{-1}\right]$,

$\mathrm{P} \quad-$ water transfer values $\left[\mathrm{m}^{3} \mathrm{~s}^{-1}\right]$,

MQ $\quad-$ minimum balance streamflow $\left[\mathrm{m}^{3} \mathrm{~s}^{-1}\right]$,

$\mathrm{X} \quad-$ impact on the flow of water users $\left[\mathrm{m}^{3} \mathrm{~s}^{-1}\right]$.

Based on the calculated BSC or BSENP values, the balance condition in Slovakia is determined in 
a monthly time step in categories $\mathrm{A}, \mathrm{B}$, and $\mathrm{C}$ as seen in Table 1.

The balance status, which is evaluated as passive or tense, is the signal to review the original measures or to develop new ones. Where there are problems, the input data are determined again, especially the data on the monitored abstractions and water utilization, as well as the streamflow data from the water gauging stations. These tasks, along with a requirement for a new course in evaluating and representing the results of the water management balance, are reasons for the testing and application of the simulation model. As an initial test of compatibility with the water management balance, all the characteristics evaluated in the balance profiles could be transformed into the outputs of the WEAP model described in Fig. 1, thus outlining its probable success.

\section{Study area}

As the second longest river flowing through the territory of Slovakia, the Hron River has a length of $298 \mathrm{~km}$, a total catchment area of $5463.5 \mathrm{~km}^{2}$, and an average altitude of $550.4 \mathrm{~m}$ a.s.1.; its most important tributary is the Slatina, with its outfall at river kilometer 153 of the Hron river (see Fig. 2). It has a length of $55.2 \mathrm{~km}$ and a total catchment area of $792.56 \mathrm{~km}^{2}$. There is a dense water gauging network of 55 stations in the whole river basin.

In terms of surface water management, 4 streams are balanced in the Hron river basin, while there are 11 balance profiles on the Hron river, 3 balance profiles on the Slatina river, one on the Zolná river, and one on the Bystrica river (a total of 16 balance profiles, 8 of which are out of the position of water gauging stations at a distance greater than $200 \mathrm{~m}$ ). The time series of the input data in the period 2000-2019 was selected for modelling the quantitative water management balance of the surface waters according to the valid methodology in the Hron river basin in a monthly time step. In the given period, 122 abstractions of surface water, 772 abstractions of groundwater, 319 water discharges, 4 reservoirs, and 2 water transfers were active.

Table 1. The classes according to the water balance condition (BSC or BSENP) of the river

\begin{tabular}{ccl}
\hline Class & $\begin{array}{c}\text { Threshold } \\
\lceil-\rceil\end{array}$ & Tension level of a river \\
\hline A & $>1.1$ & Active state - Good: appropriate use of resources (blue) \\
B & 0.9 to 1.1 & Tense state - Acceptable: need to define the causes (yellow) \\
C & $\leq 0.9$ & Passive state - Unacceptable: inappropriate and excessive use of resources (red) \\
\hline
\end{tabular}

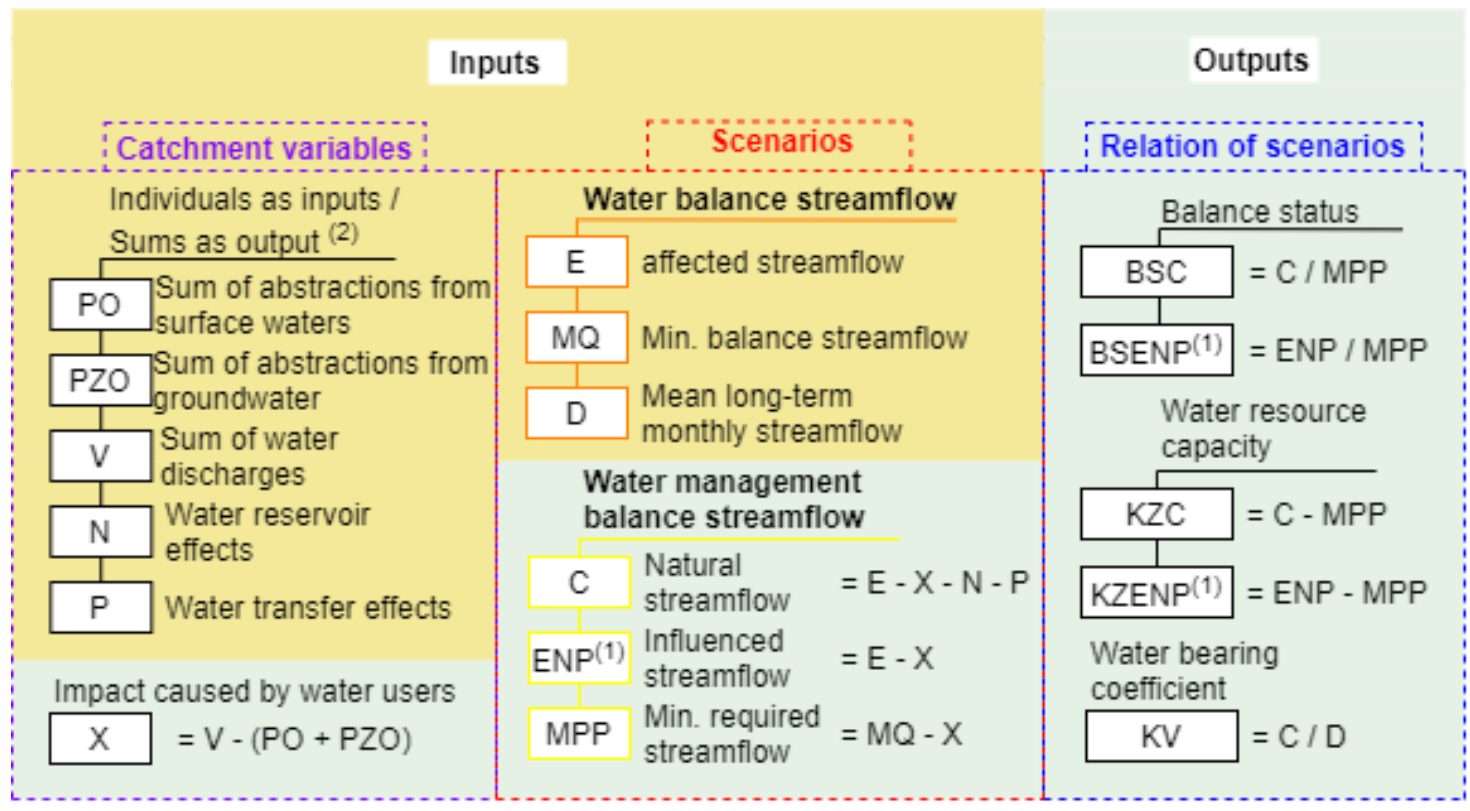

(1) Including the impact of flow manipulation on reservoirs, water transfers and distribution facilities

(2) Individual users and manipulations are inputs; their sum as individual catchment variables is the output

Fig. 1. Initial implementation of water management balance characteristics into the WEAP model. 


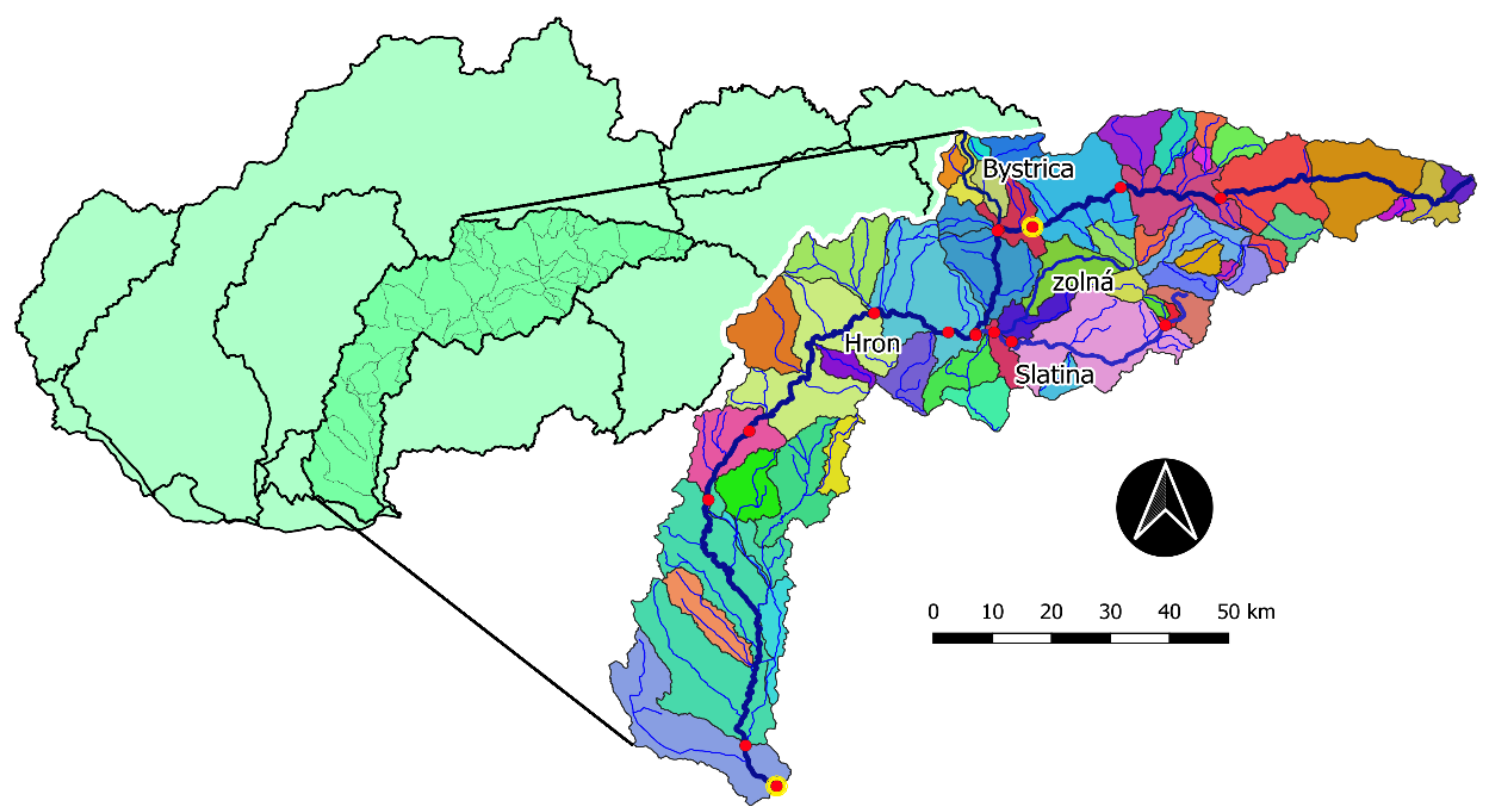

Fig. 2. Location of the Hron river basin, including balanced rivers (blue lines) and balance profiles (red points).

\section{Modelling approach and data structure}

The element that participates in the data structure for the calculation of the outflow in the "Data" part and the creation of the outflow in the scheme is the element representing the sub-basin, i.e., the "Catchment". From this element, the outflow can be distributed to the streams in several ways, which can be applied in individual scenarios. The "Runoff / Infiltration" element is used to distribute the outflow from the "Catchment" sub-basin element. With this element, it is possible to distribute a set percentage of the runoff from a given sub-basin to selected points in the streams in each sub-basin. In the scheme, the closure profiles of the sub-basins are water gauging stations with exceptional balance profiles. The outflow in the model is created by setting up the value of the precipitation variable of the catchment element. This precipitation value is calculated so that the modelled streamflow matches the streamflow data in the water gauging stations. Since the created model is purely retrospective, the streamflow data from the water gauging stations representing the affected streamflow $\mathrm{E}$ (which is the main model scenario) in the water management balance are available for the whole time period. The exceptions are water gauging stations with incomplete time series, as well as balance profiles, that are too far from nearby water gauging stations and are therefore required to have their own "Catchment" element. The total number of catchments was 55 (distinguished by the color scale on Fig. 2), i.e., 53 for the water gauging stations and 2 for the balance profiles (marked by the yellow circle on Fig. 2).

As the manipulation and users of the water are part of the model, they have to be the part of the equation calculating the precipitation value that forms the outflow from the sub-basin to the streams located in it. The simplified version of the equation is:

$$
P_{\text {precip. }}=\frac{\Delta Q+P O+P Z O-V \pm N \pm P}{A}
$$

where:

$\mathrm{P}_{\text {precip. }}$ - value of the part of the precipitation representing the outflow from the sub-basin [m converted to $\mathrm{mm}]$,

$\Delta Q$ - difference between the inflow into and the outflow from the sub-basin based on the streamflow data $\left[\mathrm{m}^{3}\right]$,

PO - summary of abstractions of surface water located in sub-basin $\left[\mathrm{m}^{3}\right]$,

PZO - summary of abstractions of groundwater located in sub-basin $\left[\mathrm{m}^{3}\right]$,

$\mathrm{V}$ - summary of water discharges located in subbasin $\left[\mathrm{m}^{3}\right]$,

$\mathrm{N}$ - summary of flow manipulations on reservoirs located in sub-basin $\left[\mathrm{m}^{3}\right]$,

$\mathrm{P} \quad$ - summary of water transfers located in sub-basin $\left[\mathrm{m}^{3}\right]$,

A - area of sub-basin $\left[\mathrm{m}^{2}\right]$.

In the case of balance profiles with their own modelled sub-basins as well as incomplete time periods of the water gauging stations concerned, the value of $P_{\text {precip. }}$. was taken from the nearby sub-basin of a water gauging station with similar morphology, as well as similar values of the average monthly precipitation.

All the individual inputs of the equation are computed as variables of the "Catchment" elements of the data structure. Fig. 3 displays the data structure of the model created including the links of the data inputs from their source to the variables of the individual elements of the water management balance (names of the variables above the arrows).

To calculate the balance status at the balance profiles, 
scenarios with the long-term values of the minimum balance streamflow (MQ) and minimum required streamflow (MPP) had to be created (see Blaškovičová, et al., 2015) for a thorough description of the method of MQ determination used). As the streamflow is based on data from the water gauging stations, but the water gauging stations did not yet have an MQ set, it was replaced with the long-term values of the 355-day streamflow $Q_{355}$. For BP2640 - Šálková and BP9800 - the Hron estuary, which does not have same location as water gauging stations, MQ was calculated by same method as the affected streamflow, E.

\section{Results and discussion}

The precision of the streamflow calculations highly depends on the correct construction of the scheme and the data structure of the model. The profiles of the water

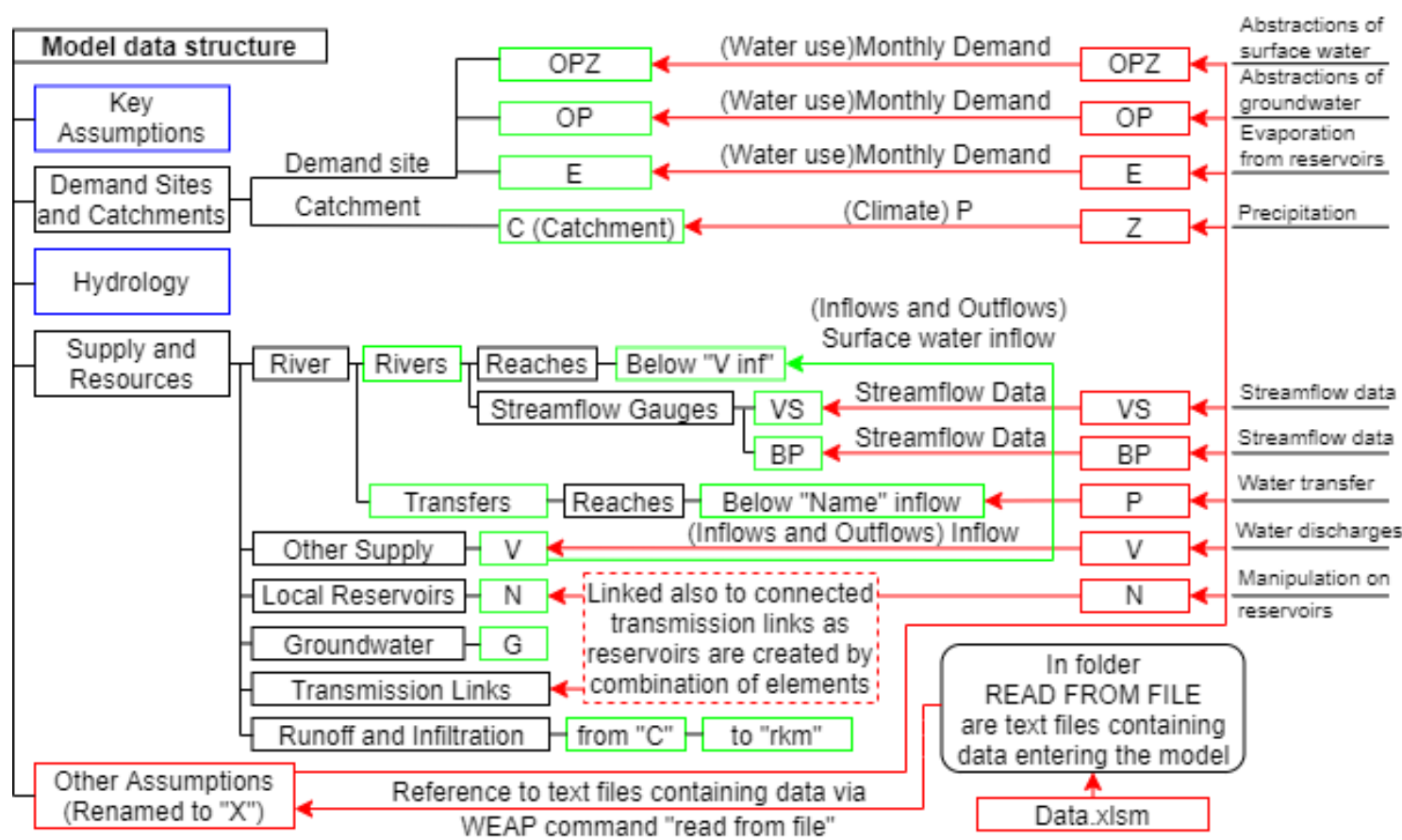

Fig. 3. The basic scheme of the data structure: Parts of the data structure without the inputs and the necessary adjustments (blue), parts of the individual elements of the scheme (green), edited and command lines used to form part of the data structure " $X$ " (red), links to the input data in the " $X$ " (red arrow)..

Table 2. Comparison of MQ and $Q_{355}$ values in the balance profiles (BP) with the same locations as the water gauging stations (WGS) on the Hron River

\begin{tabular}{|c|c|c|c|c|c|c|c|}
\hline $\begin{array}{l}\text { Registration } \\
\text { number }\end{array}$ & $\begin{array}{l}\text { Type of } \\
\text { profile }\end{array}$ & Profile name & $\begin{array}{c}\text { River km } \\
{[\mathrm{rkm}]}\end{array}$ & $\begin{array}{c}\text { Area } \\
{\left[\mathrm{km}^{2}\right]}\end{array}$ & $\begin{array}{c}Q_{355} \\
{\left[\mathrm{~m}^{3} \mathrm{~s}^{-1}\right]}\end{array}$ & $\begin{array}{c}\mathrm{MQ} \\
{\left[\mathrm{m}^{3} \mathrm{~s}^{-1}\right]}\end{array}$ & $\begin{array}{c}\text { Ratio } \\
{[\%]}\end{array}$ \\
\hline 1480R0 & $\mathrm{BP}$ & \multirow{2}{*}{ Brezno } & \multirow{2}{*}{223.3} & \multirow{2}{*}{582.08} & 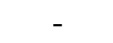 & 1.085 & \multirow{2}{*}{61.2} \\
\hline 7015 & WGS & & & & 1.773 & - & \\
\hline 2360R0 & $\mathrm{BP}$ & Nemecká & 202.2 & 1249.8 & - & 2.700 & \multirow{2}{*}{58.2} \\
\hline 7081 & WGS & Dubová & 203.1 & 1244.1 & 4.642 & - & \\
\hline $3240 \mathrm{R} 0$ & $\mathrm{BP}$ & Hron under Bystrica & \multirow{2}{*}{175.2} & \multirow{2}{*}{1766.48} & - & 4.755 & \multirow{2}{*}{63.00} \\
\hline 7160 & WGS & Banská Bystrica & & & 7.549 & - & \\
\hline $5600 \mathrm{R} 0$ & $\mathrm{BP}$ & \multirow{2}{*}{ Žiar nad Hronom } & \multirow{2}{*}{131.5} & \multirow{2}{*}{3310.62} & - & 7.025 & \multirow{2}{*}{67.4} \\
\hline 7260 & WGS & & & & 10.427 & - & \\
\hline 6950R0 & BP & \multirow{2}{*}{$\begin{array}{l}\text { Kozmálovce below } \\
\text { water reservoir }\end{array}$} & 73.4 & 4015.67 & - & 7.905 & \multirow{2}{*}{67.6} \\
\hline 7298 & WGS & & 73.1 & 4015.73 & 11.690 & - & \\
\hline $8880 \mathrm{R} 0$ & $\mathrm{BP}$ & \multirow{2}{*}{ Kamenín } & 10.7 & \multirow{2}{*}{5149.8} & - & 8.470 & \multirow{2}{*}{68.9} \\
\hline 7335 & WGS & & 10.9 & & 12.300 & - & \\
\hline
\end{tabular}


gauging stations serve as a control of this assembly, so that, when the model is correctly assembled, the modelled streamflow should be equal to the measured one. In the first step, the flows were ordered chronologically and used to calculate the differences between $Q_{\text {modelled }}$ and $Q_{\text {measured }}$. Fig. 4 shows that most of the differences are minimal, which means that, in general, the model is setting correctly. On these profiles, the percentual differences only range from -0.39 to 1.39 percent, which could be caused in part by partial errors in the model construction or incomplete input data.

The streamflow at the balance profiles without the streamflow measured from the nearby water gauging station was simulated in two ways: i) distributing the outflow to each river kilometer according to its share of the sub-basin area (BP5080, BP3920 and BP6425), or ii) by creating an individual catchment element for the sub-basin area of the balance profile (BP2640 and BP9800). A comparison of the modelled $Q_{\text {modelled }}$ and calculated streamflow $Q_{\text {calculated }}$ for the water management balance at the BP2640, balance profile of Šálková, and the BP9800, balance profile of the Hron estuary, shows that the differences are not significant, despite the simple methods used to calculate the streamflow (see Fig. 5a, b), while the balance profiles with the streamflow simulated by the distributed outflow had annual mean difference values between -0.78 to -1.36 percent, i.e., differences that are assumed to be negligible.

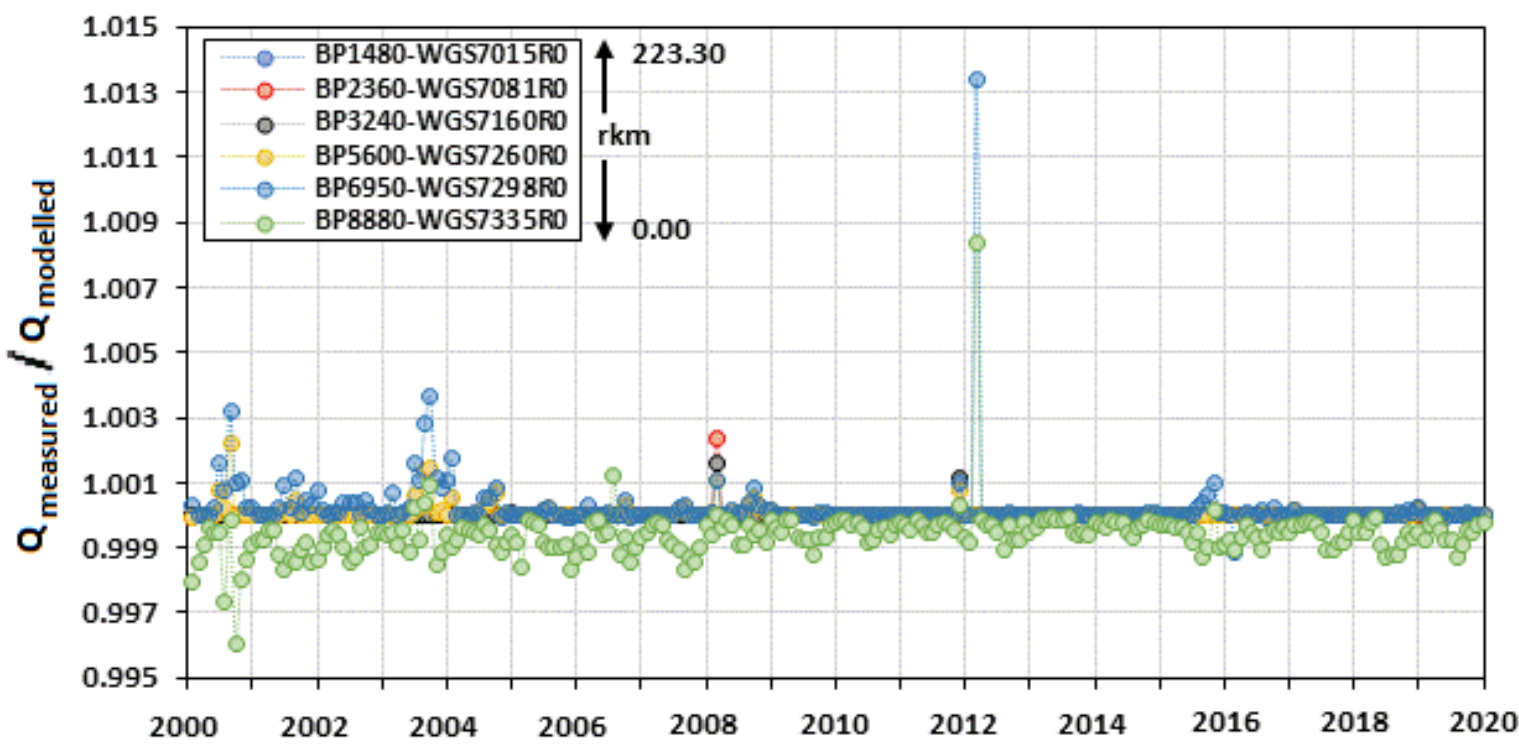

Fig. 4. Comparison of the modelled streamflow and measured streamflow at the water gauging stations which share a position with the balance profiles on the Hron river for the period 2000-2019.

a)

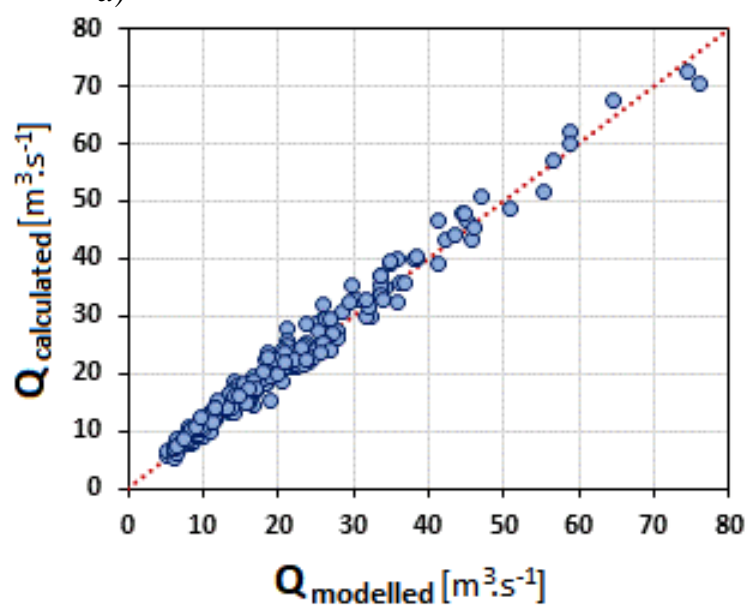

b)

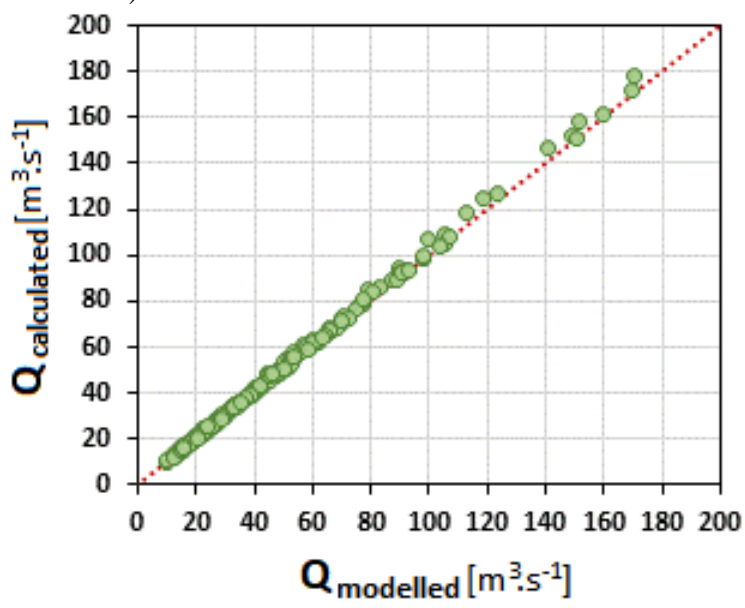

Fig. 5. Comparison of the streamflow modelled and streamflow calculated by the Slovak Hydrometeorological Institute for the water management balance in monthly time steps at the balance profiles: a) BP2640 - Šálková; b) BP9800 - the Hron estuary. 
Fig. 6 shows the color-coded states for a balanced period of 20 years in the profiles located on the river Hron, using $Q_{355}$ as MQ in BSC calculation. The active balance status (blue) was reached in 2341 months in this period on the stream, while the tension status (yellow) occurred 195 times and the passive (red) status 104 times. for comparison, using the original MQ values, the BSC values were not in the passive or tense state once throughout the 20 years period, outlining not negligible impact of using $\mathrm{Q}_{355}$ as MQ in BSC calculation. It is clear from the figure that the tense and passive balance statuses occur with a certain periodicity, while it can be assumed that this could be related to the year-on-year flow regime in the given years, as well as the occurrence of normal and dry years occurring in the river basin. This assumption is confirmed by a spectral map of the water flow in space and over time made as a ratio between the average monthly streamflow and long-term average monthly streamflow over the balance period $\left(Q_{m} / Q_{m a}\right)$, see Fig. 7. More problematic places regarding the tension

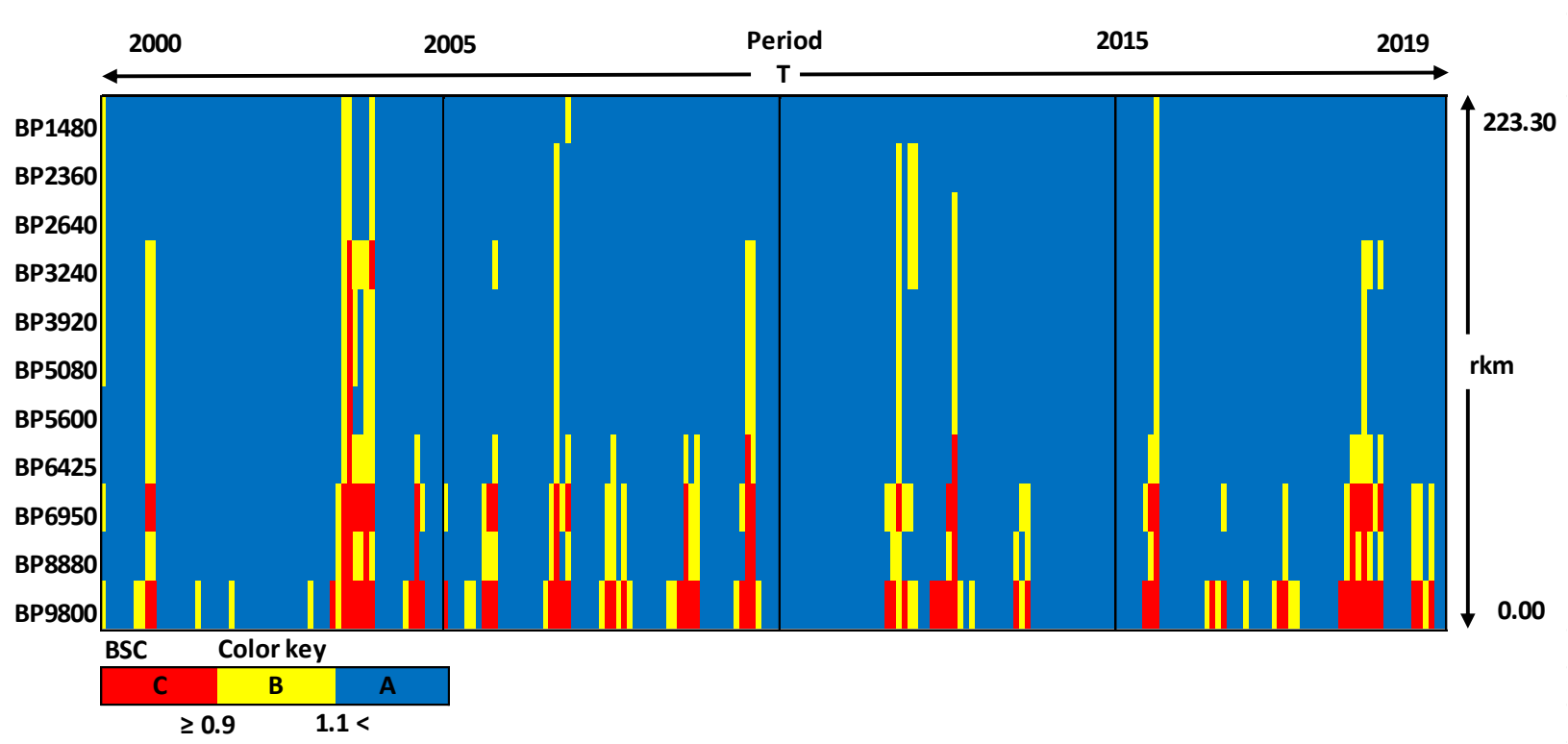

Fig. 6. Condition of balance status areas at balance profiles on the Hron river for the period 2000-2019, marked passive (red), tense (yellow) and active (blue).

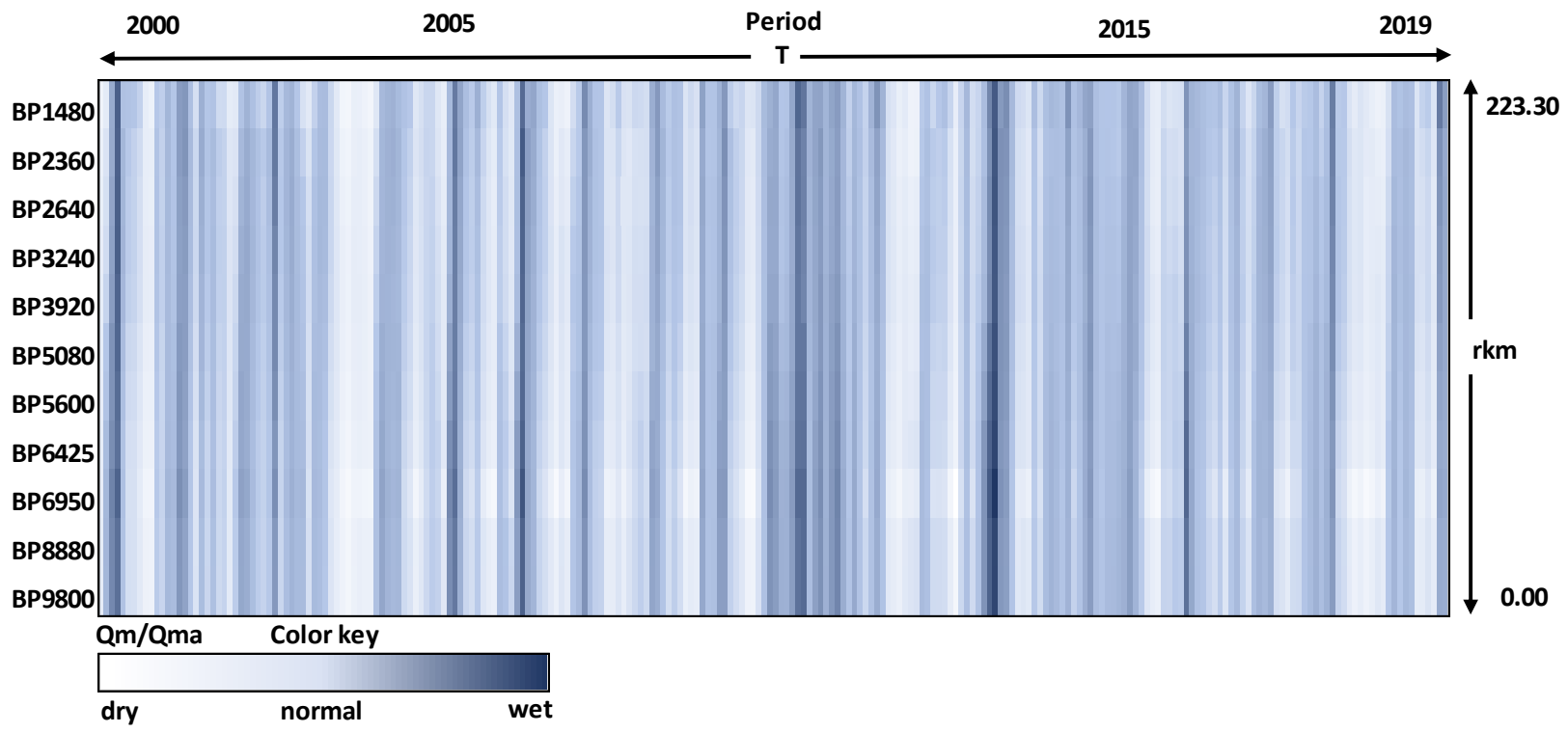

Fig. 7. Colormap of the Hron river's water content in space and over time (color spectrum from white to dark blue, or from dry to wet periods). 
of the stream are situated from the source to the outfall (from BP6425 after BP9800), which certainly affects the increasing demand for water in the southern regions of Slovakia multiplied by the occurrence of a lower water period (pale spectrum in Fig. 7).

In comparison, the long-term average monthly BSC values at the balance profiles on the Hron river very rarely get below a value of 1.1 as a tense balance status. As the monthly average BSC is lowest in September and October (see Fig. 8), while highest in March and April, it appears that that is mainly due to the hydrological regime of the streams in Slovakia.

To partially verify this statement, Fig. 9 shows the average long-term monthly effect of water use and manipulation in the years 2000-2019, as summaries for the whole catchment of the Hron river. While the abstractions have the most negative impact in June and the least negative in October, the water discharges do have higher (because they include retained rainwater), yet contrary effect, as there is a connection between them. Compared to these effects, the summaries of the water transfers and impacts of the reservoirs do not show a significant impact. The difference between the impacts shows that while it is positive the whole year, except the most negative impact in July, it does not agree with the passive BSC in September and October.

However, these statements apply only in the case of the average long-term monthly values, while the use of

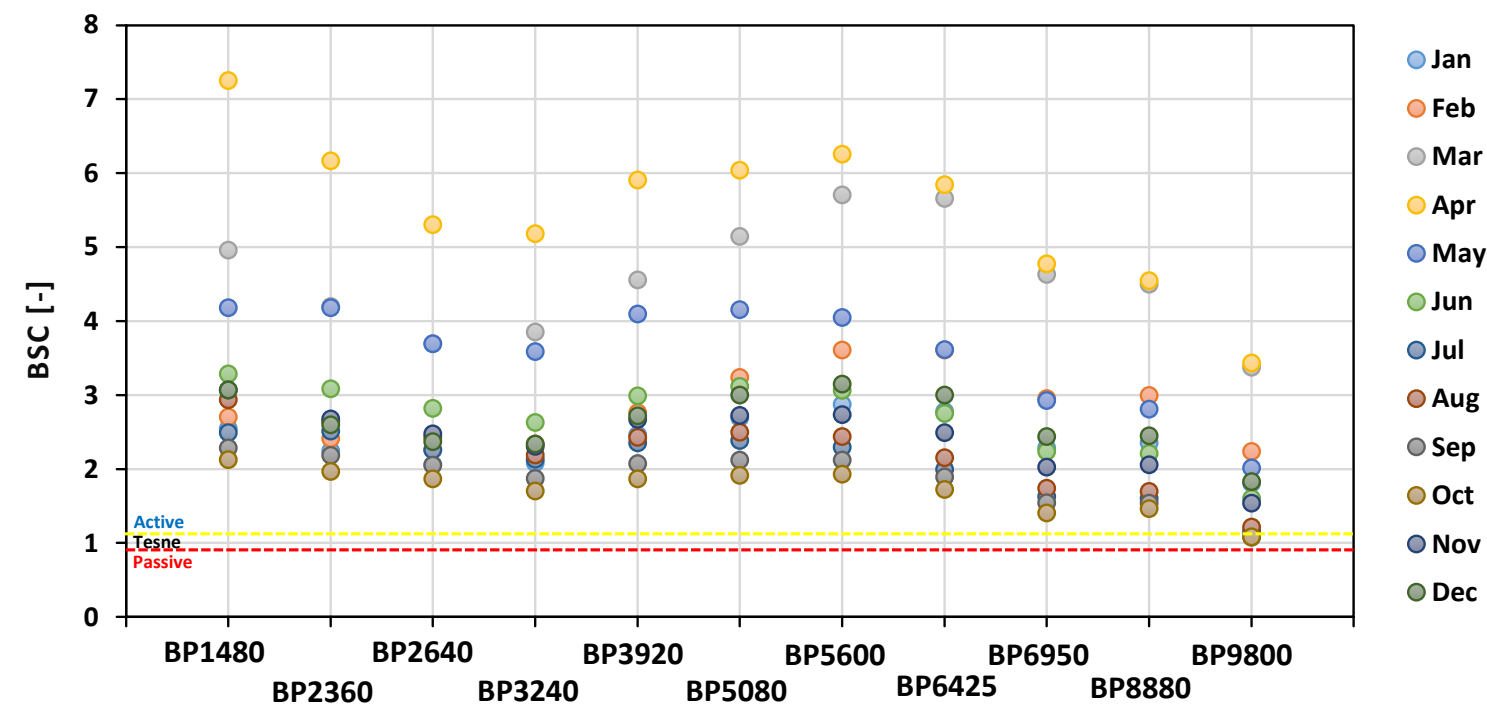

Fig. 8. Long-term average monthly BSC at the balance profiles on the Hron river for the period 2000-2019.

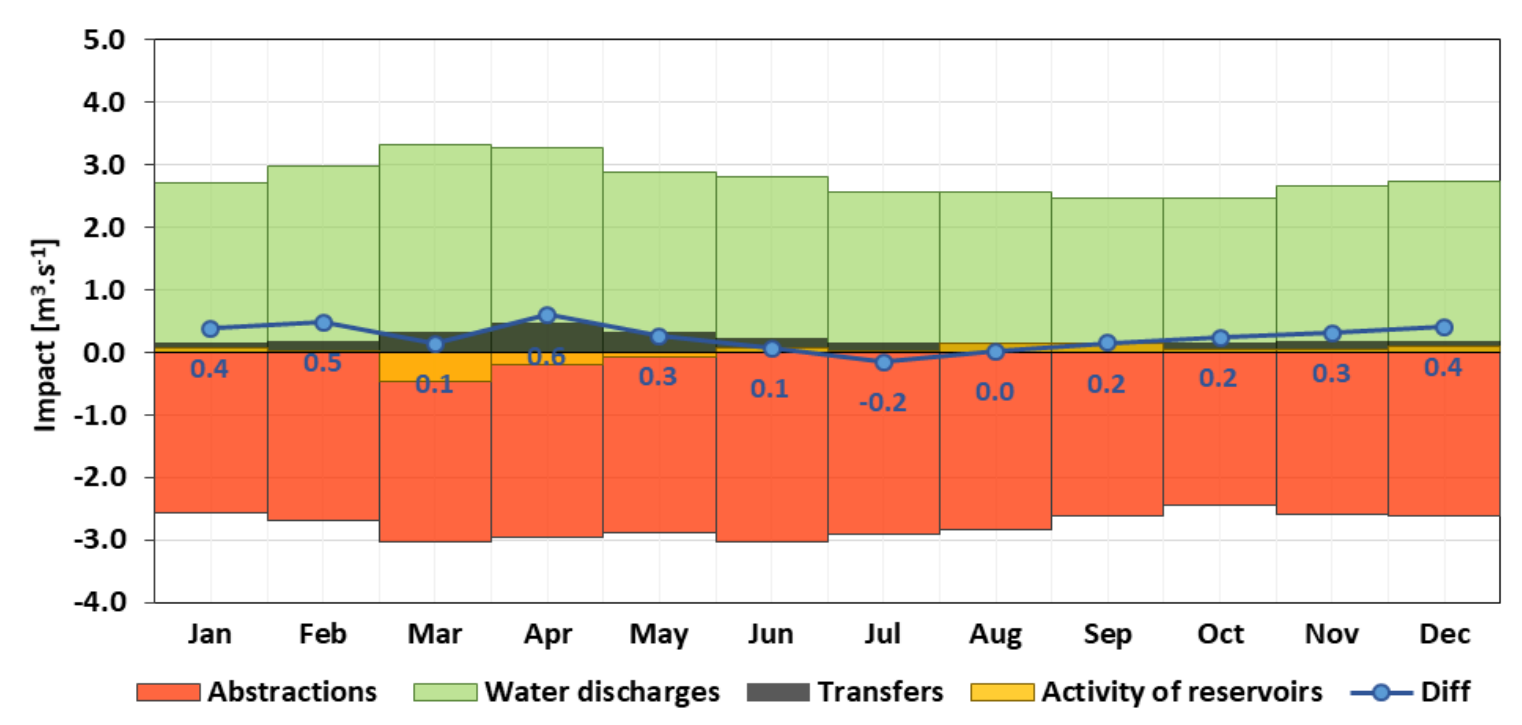

Fig. 9. Long-term average monthly summarized impact of water use and manipulation at the final profile (BP9800 - Hron estuary) for the period 2000-2019. 
water and manipulation with water can have a much greater impact in the case of the evaluation of individual years. From the perspective of the long-term trends, according to Melová et.al. (2016), the development of water use in Slovakia in the period of years 2002-2014 was declining.

\section{Conclusion}

Water management balances are one of the main activities of water management in securing water requirements and their redistribution in space and over time. The resolution of the water balance has a nonuniform form in the global understanding, not only in terms of the time step in which it is addressed in various countries, or in its methodology or method of solution, but also in the very principles that individual countries apply in water management.

This paper describes the testing and application of integrated software (Water Evaluation and Planning) designed to address the issue of the redistribution of available water resources in space and over time in our physical and geographical conditions. A balance simulation model was created in the WEAP software by working in a monthly time step for the period 2000-2019, when all the elements of the water management balance of the surface waters were modelled, and the balance status was evaluated. In addition to the distribution of runoff from the river basin, an internal model was created in the data structure, which can be used to define the modelled runoff with respect to the impact of the manipulation by the water users, i.e., a flow rate identical to the flow rate observed in the water gauging stations. Due to the methodological procedure compiled in this way, it was possible to subsequently distribute the runoff along the length of the streams, depending on the share of the area and the slope of the terrain (see Kandera and Výleta, 2020) for more about runoff distribution along a stream in WEAP). Thus, it is possible to better analyze the current methodology of the water management balance of the surface waters in the Slovak Republic and consider its modifications.

The approach applied to modelling the water balance shows its potential, especially in terms of control over the model itself. It provides an ability to model the streamflow with a full degree of accuracy if the streamflow data are available, as well as calculate it if it is not available. It is not only a hydrological model, but it can also include complex elements of water management. Along with this potential, it also requires the user to fully understand the defined properties of the model, as well as the interconnection of the individual elements of the scheme and data structure. In the case of a relatively large model such as the Hron river basin, working with the model could be challenging for the unskilled user.

The model was used in a simple analysis of the effects from the change in the minimum balance flow on the value of $Q_{355}$, and although there were no visible significant differences between the modelled and calculated flows in the balance profiles outside the water gauging stations, the simplicity of the flow calculation method in these profiles must be considered when looking at the results. A more important result is the sheer number of outputs that the model brings. In addition to its potential for supplementing the current production of water management balance outputs with a long-term time series of data, it shows its potential capability as an analytical tool, which in principle the WEAP software itself is. Consequently, its primary usefulness will be focused on the direction in which the development of the established methodology for modelling the water management balance of the amount of surface water will go.

One of the future research goals is to implement the usual method of calculating runoff from a river basin at a smaller catchment into the created methodology and to compare the results. That approach could serve subsequent goals to deal with the problems which occurred during the modelling, along with efforts to connect the water management of the amount of surface water and groundwater through modelling in the WEAP software.

Models like WEAP are based on a mathematical description of all the dependencies between the resources and requirements and permit solving them by computer technology, a number of variant changes in the resources, as well as the water requirements. Due to the mentioned fact that in Slovakia, balance simulation models have never been fully applied in practice, the outputs of this paper are assessed as necessary and considered an effort to move forward in this area within Slovakia.

\section{Acknowledgement}

This work has been funded by the Slovak Research and Development Agency under Contract No. APVV-190340, and the VEGA grant agency under Contract No. VEGA 1/0632/19. The authors are grateful for their financial support.

\section{References}

Andreu, J., Capilla, J., Sanchìs, E. (1996): AQUATOOL, a generalised decision-support system for water-resources planning and operational management. Journal of Hydrology, 177, (3-4), 269-291.

Assaf, H., van Beek, E., Borden, C., Gijsbers, P., Jolma, A., Kaden, S., Kaltofen, M., Labadie, J. W., Loucks, D. P., Quinn, N. W. T., Sieber, J., Sulis, A., Werick, W. J., Wood, D. M. (2008): Chapter thirteen: generic simulation models for facilitating stakeholder involvement in water resources planning and management: a comparison, evaluation, and identification of future needs. Developments in Integrated Environmental Assessment, 3, 229-246.

Blaškovičová, L., Melová, K., Danáčová, Z., Lovásová, L'. Šimor, V., Poórová, J. (2015): Minimum balance streamflow in relation to ecological flows. Acta Hydrologica Slovaca, 16, 23-30.

Danáčová, Z., Gápelová, V., Lovásová, L., Lupták, L., Melová, K., Podolinská, J., Rischáneková, M., Síčová, B., Staňová, J. (2011): Water resource balance of surface water quantity for 2010, SHMÚ Bratislava, 328.

DHI (2003): MIKE BASIN: A Versatile Decision Support 
Tool for Water Resources Management Planning, Guide to Getting Started Tutorial. Danish Hydraulic Institute, Denmark.

European Union (2015): Guidance document on the application of water balances for supporting the implementation of the WFD. ISBN 978-92-79-52021-1

Kaden, S., Kaltofen, M., Koch, H. (2006): Water resources management and water availability in the Elbe River Basin under conditions of global change. In: Voinov, A., Jakeman, A. J., Rizzoli, A. E. (Eds.), Proceedings of the iEMSs Third Biennial Meeting: "Summit on Environmental Modelling" and Software. International Environmental Modelling and Software Society, Burlington, VT, USA.

Kandera, M., Výleta, R. (2020): Application of the Water Evaluation And Planning (WEAP) Model to Quantitative Water Balance Modelling in the Upper Hron River Basin (Slovakia). In: IOP Conference Series: Earth and Environmental Science, Vol. 609, No. 1, p. 012055. IOP Publishing.

Labadie, J. (2005): MODSIM: River basin management decision support system. Watershed Models. CRC Press, Boca Raton, FL, USA.
Melová, K., Lovásová, L., Blaškovičová, L., Danáčová, Z. (2016): Evaluation of water use in comparison with water resources in surface waters in the period 2002-2014 based on the results of the water management balance, Presentation at international conference on the "Effective use of water resources in the conditions of the ongoing climate change (dry and water deficiencies)", under the auspices of Priority Area 4, Water Quality of the Danube Strategy and the Minister of the Environment of the Slovak Republic.

Poorová, J. (2007): Methods of water management balance. Dissertation work, STU Bratislava.

Sechi, G. M., Sulis, A. (2009): Water system management through a mixed optimization-simulation approach. Journal of Water Resources Planning and Management, 135 (3), 160-170.

WL/Delft Hydraulics, (2007): RIBASIM. http://www.wldelft.nl/soft/ribasimlint/. Last accessed on June 23, 2007.

Yates, D., Sieber, J., Purkey, D., Huber-Lee, A. (2005): WEAP21: a demand, priority, and preference driven water planning model. Part 1. Model characteristics. Water International, 30 (4), 487-500.

Ing. Miroslav Kandera ( ${ }^{*}$ corresponding author, e-mail: miroslav.kandera@stuba.sk)

Ing. Roman Výleta, PhD.

Bc. Anna Liová

Department of Land and Water Resources Management

Faculty of Civil Engineering

Slovak University of Technology in Bratislava

Radlinského 11

81005 Bratislava

Slovak Republic

Ing. Miroslav Kandera

Ing. Zuzana Danáčová, PhD.

Ing. L'ubica Lovásová

Slovak hydrometeorological institute

Jeséniova 17

83315 Bratislava

Slovak Republic 